\title{
TRIAGEM NEONATAL: \\ o conhecimento materno em uma maternidade no interior do Paraná, Brasil
}

\author{
Isabella Schroeder ABREU a, Welligton Luciano BRAGU IN I
}

\section{RESUM 0}

Estudo transversal, quantitativo, realizado no Alojamento Conjunto de um hospital de médio porte, no interior do Paraná do qual fizeram parte 40 puérperas maiores de 18 anos. T eve como objetivo analisar o conhecimento desta população sobre a finalidade e importância da realização do "teste do pezinho" e caracterizá-la sóciodemog raficamente. Os dados foram col etados em maio e junho de 2010, através de um questionário semi-estruturado elaborado e aplicado pelos próprios pesquisadores. A finalidade da triagem neonatal era conhecida por $65 \%$ $(n=26)$ das participantes, observando-se que a maioria conhecia a finalidade e sabia sobre a importância da realização do "teste do pezinho", fato este que denota a importância das orientações que devem ser dispensadas a estas mães sobre o referido assunto, mesmo antes do nascimento do bebê, com enfoque ainda no pré-natal, destacando-se a importância do papel do enfermeiro neste contexto.

D escritores: T riagem neonatal. Saúde mental. Recém-nascido.

\section{RESUMEN}

E studio transversal, cuantitativo, celebrado en alojamiento conjunto de un hospital en el interior de Paraná, B rasil, con 40 madres de más de 18 años. T uvo como objetivo examinar el conocimiento de las madres sobreel propósito y la importancia de completar la "prueba de G uthrie" y caracterizarlos socio- demográficamente. $L$ os datos se recolectaron entre mayo y junio de 2010 a través de un cuestionario, desarrollado e implementado por los investigadores. E I objetivo del cribado neonatal era conocido por el $65 \%(n=26)$ de los partici pantes, la mayoría sabía queel propósito y la importancia de completar la "prueba de G uthrie", que demuestra la importancia de las di rectrices quedebe ser puesto a las madres sobreel tema, antes del nacimi ento del bebé, enfocado en la atención prenatal, haciendo hincapié en la importancia del papel de las enfermeras en este contexto.

Descriptores: Tamizaje neonatal. Salud mental. R ecién nacido.

T ítulo: E I cribado neonatal: conocimiento del madres en un maternidad en el interior del Paraná, B rasil.

\section{ABST RACT}

This is a cross-sectional quantitative study quantitativeheld in the rooming area of a medium-sized hospital in thehinterlands of Paraná, B razil. 40 mothers over 18 years participated in the study. The study aimed to examine what this population knows about the purpose and importance of completing the "Guthrie test" and also to characterize these mothers sociodemographically. The data were collected in M ay and J une 2010 through a semi-structured questionnaire developed and implemented by the researchers themsel ves. Thepur pose of neonatal screening was know $n$ by $65 \%(n=26)$ of the participants. T he majority of them knew the purposeand knew about the importance of completing the "G uthrie test", a fact which shows the importance of the orientations these mothers must have on this subject even before the birth of the baby, still focusing on prenatal care, and emphasizing the importance of the role of nurses in this context.

D escriptors: $N$ eonatal screening. M ental health. Infant, new born.

T itle: N eonatal Screening: what mothers know about it in a maternity in the hinterland of the state of Paraná, B razil.

\footnotetext{
a M estre em Enfermagem em Saúde Pública, D outoranda pelo Programa de Pós-Graduação em Enfermagem em Saúde Pública da E scola de E nfermagem de Ribeirão Preto da U niversidade de São Paulo (E E R P / U SP), D ocente do Curso de Graduação em E nfermagem da Univer sidade E stadual do Centro-Oeste (U nicentro), Guarapuava, Paraná, Brasil.

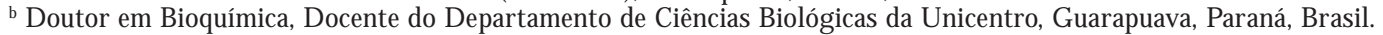




\section{INT RODUÇÃO}

A T riagem N eonatal ( $\mathrm{TN}$ ) é um dos vários programas de triagem populacional existentes. A tualmente, é empregada tanto para o diagnóstico precoce (no período neonatal, ou seja, entre 0 a 28 dias de vida) de doenças genéticas - geralmente erros inatos do metabolismo, hematológicas, infecciosas, genéticas, etc ${ }^{(1-3)}$. A idade da criança no momento da coleta é um fator restritivo na triagem da fenilcetonúria, pois crianças com menos de 48 horas de vida ainda não ingeriram proteína suficiente para serem detectadas de forma segura na triagem da fenilcetonúria, assim sendo, o período ideal para coleta deve ser superior a 48 horas de vida(4).

A T N foi incorporada ao Sistema Ú nico de Saúde (SU S) no ano de 1992 (Portaria G M / M S no 22/92)(5) com uma legislação que deter minava a obrigatoriedade do teste em todos os recémnascidos vivos e incluía a avaliação para Fenilcetonúria e Hipotireoidismo Congênito(6,7).

No ano de 2001, o M inistério da Saúde, através da Secretaria de Assistência à Saúde, empenhou-se na reavaliação da T N no SU S, o que culminou na publicação da portaria ministerial (Portaria G M / M S no 822/ 01) $)^{(8)}$ que criou o Programa $\mathrm{N}$ acional de T riagem N eonatal (PNTN).

D entre os principais objetivos do programa, destacam-se a busca da cobertura de $100 \%$ dos nascidos vivos e a definição de uma abordagem mais ampla da questão, determinando que o processo de T N envolva várias etapas como: a realização do exame laboratorial, a busca ativa dos casos suspeitos, a confirmação diagnóstica, o tratamento e 0 acompanhamento multidisciplinar especializado dos pacientes, além da ampliação da gama de agravos de saúde triados (Fenilcetonúria, H ipotireoidismo Congênito, A nemia $\mathrm{Falciforme} \mathrm{e} \mathrm{outras} \mathrm{He}$ moglobinopatias e F ibrose Cística). D essa forma, o PNT N cria o mecanismo para que seja al cançada a meta principal, que é a prevenção e redução da morbimortalidade provocada pelas patologias triadas.

0 processo do PNTN envolve as estruturas públicas nos três níveis de governo, municipal, estadual e federal proporcionando uma mobilização ampla em torno das ações relacionadas à T N como um programa de Saúde Pública em nosso país.

$P$ ara que um Programa de T riagem N eonatal consiga atingir plenamente os seus objetivos, é es- sencial que algumas metas sejam cumpridas: coleta da amostra sangüínea obtida corretamente e em tempo adequado; encaminhamento rápido da amostra ao laboratório de referência; realização dos exames pelo laboratório obedecendo a rigoroso controle de qualidade; rápida comunicação dos resultados dos exames; centro de referência dotado de médico(s) treinado(s) para estabelecer(em) o diagnóstico preciso e de estrutura para o seguimento clínico das crianças afetadas; avaliações pe riódicas da qualidade do prog rama, reportando-se os resultados destas avaliações às autoridades responsáveis, a fim de que eventuais melhorias possam ser implementadas ${ }^{(1)}$.

No Paraná, o Serviço de Referência em T N é a F undação E cumênica de Proteção ao Excepcional (FEPE), uma instituição privada e filantrópica, cuja missão é a pesquisa, prevenção, diagnóstico, bem como a educação, habilitação, reabilitação e integração das pessoas portadoras de deficiência; realiza sua missão há trinta anos, através de diversos programas como a Escola E cumênica (sede e subsede), Estimulação Precoce, atendimento a portadores de M últipla D eficiência, a Profissionalização e o Centro de Pesquisas( ${ }^{(6)}$. Vale salientar que esta instituição realiza ainda cursos de capacitação para profissionais de saúde sobre T N .

A FEPE que iniciou suas pesquisas para Fenilcetonúria em 1981 como projeto piloto em Curitiba, expandindo-se em 1987 com a pesquisa também do Hipotireoidismo Congênito ${ }^{(3)}$, através da L ei Estadual $n$ ㅇ 8627/ 87(9). A tualmente, com a nova Portaria do M inistério da Saúde $n-822 / 01^{(8)}$, a FEPE em parceria com o SUS, examina em mé dia 180.000 crianças por ano, pesquisando as quatro enfer midades determinadas pelo PNT N e tria também para a Deficiência da Biotinidase, com ônus exclusivo para a FEPE, atingindo todos os municípios do Estado(3).

0 exame laboratorial realizado com a amostra de sangue coletado do recém-nascido detecta precocemente doenças metabólicas, genéticas e infecciosas, que poderão causar alterações no desenvolvimento neuropsicomotor do bebê. Esse exame é popularmente conhecido como "teste do pezinho", pois a coleta do sangue é feita a partir de uma pequena punção no calcanhar do bebê. Esse exame é realizado em grande parte nas maternidades quando o bebê completa 48 horas de vida. Antes disso, o teste pode sofrer influência do me tabolismo da mãe. 0 exame também é feito em la- 
boratórios; 0 ideal é que o teste seja feito até 0 sétimo dia de vida. Basta apenas uma picada no calcanhar do bebê para retirar algumas gotinhas de sangue que serão colhidas num papel filtro e analisadas em laboratório.

A T N ou "T este do Pezinho" é um exame gratuito, realizado em qualquer unidade de saúde, que pode trazer muitos benefícios para a criança. A pós a coleta da amostra de sangue da criança, esta é enviada a um laboratório para ser analisada e o resultado volta para a unidade em que foi realizada a coleta.

0 objetivo deste estudo foi analisar o conhecimento de puérperas sobre a finalidade e importância da realização do "teste do pezinho" e caracterizá-las segundo variáveis sócio-demográficas. 0 mesmo justifica-se tendo em vista a importância do diagnóstico precoce das enfermidades com finalidades primordiais de assessorar o lactente para o seu bom desenvolvimento físico, psicológico e intel ectual, sendo que para isto é de fundamental importância que a família conheça a importância desta triagem. Nos dados encontrados observamos que a maioria das mães participantes do estudo conhecia a finalidade e sabia sobre a importância da realização do "teste do pezinho". D estaca-se, portanto a importância da atuação do profissional de enfermagem, o qual deve ter profundo conhecimento sobre a $\mathrm{TN}$, visando à questão da orientação dessas mães, tendo em vista sua interação direta com a clientela alvo: mãe e recémnascido, além de seu papel enquanto multiplicador do conhecimento entre a equipe de saúde com quem trabalha.

\section{MATERIAIS E MÉT ODOS}

Estudo descritivo, transversal de caráter quantitativo, realizado no setor de Alojamento Conjunto $(A C)$ de um hospital de médio porte, no município de Guarapuava, Paraná. F izeram parte do estudo 40 puérperas, cuja amostra foi estabelecida mediante os seguintes critérios: ter 18 anos ou mais, residirem em Guarapuava, ter realizado pelo menos uma consulta de prénatal, que se encontravam internadas no AC da instituição, e que aceitaram participar do estudo, mediante a assinatura do Termo de Consentimento Livre e Esclarecido ( $T$ CLE). Todas as mães referiram realizar o pré-natal em consultório médico particular e nas U nidades Básicas de Saúde (UBS). Os dados foram coletados nos meses de maio e junho de 2010, através de um questionário semi-estruturado elaborado pelos pesquisadores, com base em um instrumento utilizado em um estudo real izado no E stado de $M$ inas Gerais, na cidade de Pouso Alegre, para avaliação do nível de conhecimento de mães sobre a fenilcetonúria e 0 teste do pezinho ${ }^{(10)}$. 0 presente questionário foi constituído de questões fechadas referentes aos dados sócio-demográficos e abertas referentes ao conhecimento sobre "teste do pezinho": como recebeu as informações, quando o teste é realizado, qual sua finalidade, como é realizado e quando o resultado foi obtido. Foram consideradas como variáveis sócio-demográficas: idade, escolaridade, profissão, estado civil e número de consultas de pré-natal.

A o final das entrevistas os dados obtidos foram organizados em planilha M icrosoft $E \times \mathrm{xcel}^{\circledR} \mathrm{e}$ descritos segundo estatística descritiva. 0 estudo foi realizado mediante a autorização da direção geral da instituição sediadora e aprovado pelo Comitê de Ética em Pesquisa da U niversidade Estadual do Centro-O este (UNICENTRO), parecer 119/2010, de acordo com as normas regulamentadoras de pesquisa envolvendo seres humanos.

\section{RESULT ADOS}

Para uma melhor compreensão do estudo, considerou-se necessário a exposição das variáveis sócio-demográficas das participantes e dos dados referentes ao conhecimento das mesmas sobre a $T N$, seguidos de posterior discussão:

Os resultados encontrados mostraram que as mães apresentaram uma média de idade de 29,1 \pm 6,5 anos, 50\% eram casadas, 27,5\% não haviam concluído 0 ensino fundamental e fizeram em média 8,4 consultas no pré-natal.

No presente estudo, a finalidade da T N era conhecida por $65 \%(n=26)$ das participantes, sendo que $35 \%$ desconheciam seu objetivo, $45 \%$ informaram que obtiveram conhecimento sobre a realização do "teste do pezinho", através de profissionais de saúde do hospital por ocasião do nascimento anterior de outros filhos.

Quando questionadas sobre quando o teste deve ser realizado, $45 \%(n=18)$ sabiam que 0 teste deve ser realizado até $48 \mathrm{~h}$ ou na alta hospitalar e em relação à forma como o sangue é coletado, $82,5 \%$ ( $n=33$ ) das mães sabiam informar como esta é realizada, traduzindo-se nas mais di- 
versas falas como: "um furinho no pé", "uma picadinha no pezinho do bebê", etc.

\section{DISCUSSÃO}

\section{A triagem neonatal e o teste do pezinho}

As mães quando questionadas sobre a finalidade do teste referiam que era para "detectar doenças no bebê" ou ainda para "ver se o bebê não tem retardo mental", porém não sabiam definir ou especificar quais as doenças que são triadas através do exame, fato este que denota a importância das orientações que devem ser dispensadas a estas mães sobre o referido assunto, mesmo antes do nascimento do bebê, com enfoque ainda no prénatal. É importante salientar que muitas vezes também por falta de conhecimento, algumas mães e até mesmo profissionais de saúde, referem-se a T N, como sendo a impressão plantar do bebê. Segundo - A merican College of M edical G enetics (ACM G) é necessário atentar para a educação dos profissionais de saúde e do público sobre a T N ${ }^{(11)}$. Desta for ma, a T N tem que ser observada como algo mais do que a realização de testes laboratoriais. Os profissionais da área devem entender a T N como um complexo de variáveis que vão desde a finalidade do teste, passando pelas doenças que estão incluídas, questões científicas e éticas até políticas públicas envolvidas ${ }^{(12)}$. D este modo, o profissional da saúde poderá informar ao público com segurança sobre o teste e suas etapas, bem como as implicações na família que as doenças detectadas podem ocasionar.

N este sentido, destaca-se a participação do profissional de enfermagem, o qual tem fundamental importância no PNT N, tendo em vista sua inter ação direta com a mãe e o recém nascido.

A T N é um meio de se diagnosticar precocemente diversas doenças congênitas que não apresentam sintomas no período neonatal, a fim de intervir no seu curso natural, impedindo a instalação dos sintomas decorrentes dessas. Sua história teve início no final da década de 50 , porém, só a partir da década de 60, os Programas de T riagem $\mathrm{N}$ eonatal começaram ser instalados em diversos países $^{(13)}$.

O PNTN para pesquisa da Fenilcetonúria (PKU), H ipotireoidismo Congênito, Fibrose Cística, A nemia Falciforme e outras Hemoglobinopatias, conhecido como "T este do Pezinho", foi cria- do e implementado no Brasil pela Portaria do $\mathrm{M} \mathrm{i-}$ nistério da Saúde M G / M S no 822/ 01 ${ }^{(8)}$ e tem como objetivo detectar e tratar precocemente doenças, que se prevenidas evitam sequelas como a deficiência mental e outras(3).

E $m$ relação ao conhecimento das mães sobre a realização do "teste do pezinho", estas relatam que este se deu através de profissionais de saúde do hospital por ocasião do nascimento anterior de outros filhos. 0 fato das mães apenas terem conhecimento sobre 0 assunto somente no ambiente hospitalar, mesmo que por ocasião de outras gestações é um fator que nos faz repensar enquanto profissionais de saúde a questão das orientações e informações que deveriam ter sido dispensadas a esta população a respeito da T N ainda no pré-natal.

0 pré-natal é o período, em que as gestantes, através da atuação dos profissionais de saúde devem ser informadas, conscientizadas e sensibilizadas através do conhecimento técnico-científico dispensado por estes profissionais sobre as enfermidades pesquisadas no teste do pezinho e as seqüelas irreversíveis, quando não-diagnosticadas e tratadas precocemente. Os profissionais de saúde, principalmente da enfer magem, devem conscientizarse da importância e responsabilidade do seu papel na questão da prevenção(3).

É sabido que a triagem neonatal apresenta valor inquestionável como política de saúde pública, sendo obrigatória na maioria dos países ${ }^{(14-16)}$. N 0 entanto, para alcançar seu principal objetivo, que é estabel ecer o diagnóstico e iniciar o tratamento destas doenças o mais precocemente possível, é importante que existam padrões de tempo para cada etapa do processo de rastreamento, uma vez que atrasos em uma ou mais etapas levarão a retardos inaceitáveis no tratamento das crianças afetadas ${ }^{(17,18)}$.

Quanto à forma de coleta do sangue, esta é realizada através da "punção" com lanceta no pezinho do bebê, sendo considerada absolutamente eficaz, sendo possível a obtenção da quantidade necessária de sangue para a realização do exame da amostra colhida.

A técnica correta de coleta das amostras de sangue para o "T este do Pezinho" é um procedimento de enfermagem, estando o profissional ciente como e por que irá fazer a coleta, devendo seguir criteriosamente a técnica adequada. A quecer sempre o pezinho do bebê com bolsa de água morna ou compressa morna, para melhor obten- 
ção do sangue. Fazer anti-sepsia no local correto do pé, com 0 algodão ligeiramente umedecido no álcool 70\%, puncionar com lanceta estéril e descartável num movimento único e firme; desprezar sempre a primeira formação de gota de sangue; não comprimir demasiado, evitando a hemólise e iniciar a coleta, deixando sempre o sangue pingar no papel filtro, observando os círcul os e o preenchimento completo nos dois lados do papel.

E m um estudo sobre o conhecimento materno acerca da $T \mathrm{~N}$, realizado pelo $\mathrm{D}$ epartamento de Pediatria da U niversidade de Chicago, os resultados encontrados mostraram que apenas 35\% das mulheres avaliadas receberam informações sobre a T N no pré-natal, e $56 \%$ no berçário ${ }^{(19)}$. D iferentemente dos dados obtidos em nosso estudo onde $45 \%$ das mulheres foram informadas sobre a realização do "teste do pezinho", através de profissionais de saúde do hospital por ocasião do nascimento anterior de outros filhos.

\section{CONCLUSÕES}

A finalidade e importância da realização do T este do Pezinho eram conhecidas pelas mães participantes do estudo, mesmo não conhecendo as enfer midades, suas etiologias e suas manifestações. Quanto ao tempo de real ização da coleta do exame, $45 \%$ referiram ser realizada na al ta hospitalar, porém não sabiam expressar qual a finalidade da realização do teste neste período; em contrapartida tinham conhecimento sobre a forma como o sangue era coletado.

Diante do exposto, destaca-se a importância e necessidade de orientação das gestantes durante o pré-natal e também o preparo e educação continuada dos profissionais de saúde, fortalecendo 0 conhecimento sobre a triagem neonatal.

Pretendemos despertar, através deste artigo, a atenção dos profissionais de saúde, principalmente dos enfermeiros, que atuam no atendimento do recém-nascido, da gestante, da parturiente e da puérpera, sobre a importância do diagnóstico precoce das enfermidades pesquisadas no PNT N.

Neste momento, a orientação da equipe de enfermagem à mãe é elemento crucial para salvaguardar a criança de eventuais danos ocasionados pelas doenças detectáveis ${ }^{(20)}$. A importância do exame, o esclarecimento sobre a finalidade da coleta e o procedimento em si e a necessidade de buscar o resultado do exame são orientações que, duran- te a assistência, permitem à mãe a sensação de segurança, ofer ecendo a ela saber es que consolidam a responsabilidade no sentido de promover 0 bemestar e apoio à saúde de seu filho.

\section{REFERÊ NCIAS}

$1 \mathrm{M}$ agalhães $P$, T urcato $M$, Angulo I, M aciel L. Programa de T riagem $\mathrm{N}$ eonatal do $\mathrm{H}$ ospital das Clínicas da F aculdade de $M$ edicina de Ribeirão Preto, U niversidade de São Paulo, Brasil. Cad Saúde Pública. 2009; 25:445-54.

2 Carvalho T, Santos H, Santos I, Vargas P. N ewborn screening: a national public health programme in Brazil. J Inherit M etab D is. 2007;30(4):615.

3 M arton M, Lacerda M. Teste do Pezinho: por que coletar na alta hospitalar. Rev Eletrônica Enferm. 2003;5(2):60-4.

4 M inisterio da Saúde (BR ), Secretaria de A ssistência à Saúde, Coordenação-G eral de A tenção E specializada. $M$ anual de normas técnicas e rotinas operacionais do Programa Nacional de Triagem N eonatal. Brasília (DF); 2002.

5 M inistério da Saúde (BR ). Portaria G M / M S no 22, de 15 de janeiro de 1992: trata do prog rama de diagnóstico precoce do hipotireoidismo congênito e fenilcetonúria. Brasília (DF); 1992.

$6 \mathrm{M}$ arton $M$, Z Zagonel I, Lacerda M . A enfermagem na triagem neonatal. A cta Sci H ealth Sci. 2003;25(2)15561.

7 Botler J, Camacho L, Cruz M, George P. Triagem neonatal: 0 desafio de uma cobertura universal e efetiva. Ciênc Saúde Colet. 2010;15(2):493-508.

8 M inistério da Saúde (BR ). Portaria G M / M S no 822, de 06 de junho de 2001: institui o Programa $\mathrm{N}$ acional de T riagem N eonatal (PNT N). Brasília (D F ); 2001.

9 Paraná. Lei Estadual no 8627, de 09 de dezembro de 1987: torna obrigatória a real ização do Teste do Pezinho no Estado do Paraná. Curitiba; 1987.

10 Souza K, Zanin G, Brasileiro 0. 0 conhecimento das mães a respeito da fenilcetonúria e do teste do pezinho. Sinop Pediatr. 2002;8(2):27-30.

11 A merican College of M edical Genetics. Newborn screening: toward a uniform screening panel and system. Pediatrics. 2006;117(5 Pt 2):S296-307. 
12 Leão L, Aguiar M. N ewborn screening: what pediatricians should know.J Pediatr. 2008;84(4):80-90.

13 Siqueira I, Bonamigo T. Programas de rastreamento: 0 que são? Qual o seu valor? Pesqui M éd. 1995; 29(1):10-5.

14 Pollitt R, G reen A, M cCabe C, Booth A, Cooper N, Leonard J, et al. N eonatal screening for inborn errors of metabolism: cost, yield and outcome. Health Technol Assess. 1997;1(7):1-202.

15 LaF ranchi S. Detecção neonatal de hipotireoidismo congênito: uma história de sucesso? Arq Bras Endocrinol M etab. 1995;39:80-8.

$16 \mathrm{~L}$ oeber J. N eonatal screening in E urope: the situation in 2004. J Inherit M etab D is. 2007;30(4):430-8.

17 A merican A cademy of Pediatrics, Rose S; Section on Endocrinology and Committee on Genetics,
A merican Thyroid Association, Brown RS; Public $\mathrm{H}$ ealth Committee, Lawson W ilkins Pediatric Endocrine Society. U pdate of newborn screening and therapy for congenital hypothyroidism. Pediatrics. 2006;117(6):2290-303.

18 Bongers-Schokking J, Koot H, W iersma D, Verkerk $P, M$ uinck K eizer-SchramaS. I nfluence of timing and dose of thyroid hormone replacement on development in infants with congenital hypothyroidism. J Pediatr. 2000;136:292-7.

19 Lang C, Stark A, Acharya K, Ross L. M aternal knowledge and attitudes about newborn screening for sickle cell disease and cystic fibrosis. A m J M ed Genet A. 2009;149A (11):2424-9.

20 A morim J, Souza M . 0 conhecimento das mães acerca da triagem neonatal. Rev Enferm U ERJ. 2005;13: 27-31.
Endereço da autora / Dirección del autor / Author's address:

I sabella Schroeder A breu

Rua Brigadeiro Rocha, 1141, ap. 204

85010-210, G uarapuava, PR

E-mail: i_enf@yahoo.com.br
Recebido em: 07/ 04/ 2011

A provado em: 30/ 08/ 2011 